\title{
PENGARUH KUALITAS LAYANAN TELLER BANK
}

TERHADAP KEPUASAN NASABAH SIMPEDES

PADA PT.BANK RAKYAT INDONESIA

(Persero), Tbk. KANTOR CABANG

\section{MAKASSAR TAMALANREA}

LISA ARIANA PUTRI, ( DR. ROSNAINI DAGA, S.E.,M.M.)

INSTITUT BISNIS DAN KEUANGAN NITRO

Lisaarnptr22@gmail.com

\begin{abstract}
ABSTRAK
Judul penelitian ini adalah " PENGARUH KUALITAS

LAYANAN TELLER BANK TERHADAP KEPUASAN

NASABAH SIMPEDES

PADA PT.BANK RAKYAT INDONESIA

(Persero), Tbk. KANTOR CABANG MAKASSAR

TAMALANREA ". Penelitian ini bertujuan untuk mengetahui kualitas layanan teller pada PT. Bank Rakyat Indonesia (Persero) cabang Makassar Tamalanrea. Jenis penelitian ini adalah penelitian kuantitatif yang bersifat untuk mengenmbangkan teori, kemudian data diperoleh dari observasi secara langsung di lapangan, baik berupa lisa maupun tertulis ( dokumen )
\end{abstract}




\section{I.PENDAHULUAN}

Perbankan merupakan salah satu lembaga keuangan kepercayaan masyarakat yang memegang peranan penting dalam sistem perekonomian pada suatu negara. Seiring dengan perkembangan zaman, persaingan industri jasa perbankan di Indonesia semakin ketat. Bank yang ingin unggul harus dapat memberikan produk berupa barang atau jasa yang berkualitas dan pelayanan yang baik kepada konsumen. Hal ini bertujuan untuk mendapatkan calon nasabah dan mempertahankan nasabah yang sudah ada agar tidak berpindah ke bank pesaing. Bank sebagai perusahaan yang bergerak dibidang jasa harus memberikan pelayanan yang baik dan benar kepada para nasabahnya, karena dengan pelayanan yang baik dan benar akan merangsang masyarakat untuk tertarik menjadi nasabah.

Bank menurut Undang-Undang No 10 Tahun 1998 adalah badan usaha yang menghimpun dana dari masyarakat dalam bentuk simpanan dan menyalurkannya kepada masyarakat dalam bentuk kredit dan atau bentuk-bentuk lainnya dalam rangka meningkatkan taraf hidup rakyat banyak. Dengan ini dapat disimpulkan bahwa usaha perbankan meliputi tiga kegiatan, yaitu menghimpun data, menyalurkan dana dan memberikan jasa bank lainnya

Dengan adanya revolusi teknologi komunikasi dan informasi mengakibatkan terjadinya persaingan global yang sangat luar biasa untuk dunia keuangan, salah satunya adalah perbankan. Oleh karena itu, agar tetap dapat bertahan hidup ditengah persaingan yang kompetitif salah satu strategi yang dapat menunjang keberhasilan bisnis disektor perbankan adalah dengan cara berusaha meningkatkan kualitas layanan melalui perananTeller. Karena bagian tersebut yang paling sering didatangi oleh nasabah untuk melakukan transaksi. Mengingat pentingnya menjaga kualitas 
pelayanan bank terhadap nasabahnya dalam rangka menjawab tantangan dalam persaingan dewasa ini maka bank harus selalu mampu mengukur sejauh mana kualitas pelayanan yang mereka berikan, juga tingkat kepuasan nasabah atas hasil dari pelayanan yang telah diberikan.

Dalam pelayanan yang diberikan kepada nasabah, pelayanan dari teller sebuah bank merupakan bagian yang sangat berpengaruh terhadap pelayanan keseluruhan, karena hampir sebagian besar nasabah perbankan yang mendatangi bank bertujuan untuk melakukan transaksi perbankan di counter teller. Oleh karena itulah peranan Teller sangat penting terhadap reputasi pelayanan sebuah bank, sehubungan dengan sebagian besar nasabah mengunjungi counter teller untuk bertransaksi, maka bank harus selalu memperhatikan kualitas pelayanan dari tellernya agar tercapai kepuasan nasabah tanpa harus mengesampingkan aspek keamanan dan kehati-hatian.

Salah satu Bank yang mempunyai citra perusahaan yang baik, mempunyai produk perbankan yang beragam serta aktif dalam memberikan pelayanan prima yaitu PT Bank Rakyat Indonesia (Persero), Tbk atau lebih sering dikenal sebagai Bank BRI. Bank BRI merupakan salah satu bank milik pemerintah yang terbesar di Indonesia. Bank BRI merupakan bank yang melakukan kegiatan perbankan yang terbaik dengan mengutamakan pelayanan kepada segmen mikro, kecil, dan menengah untuk menunjang peningkatan ekonomi masyarakat. Dengan memberikan pelayanan prima kepada nasabahnya maka diharapkan dapat mempertahankan serta mendongkrak jumlah nasabah yang merasa puas dengan pelayanan dan produk yang ditawarkan BRI.

Saat ini BRI masih menjadikan Simpedes sebagai prioritas utama dalam kegiatan bisnisnya. Upaya peningkatan pelayanan, khususnya pada bidang Teller terus dilakukan untuk memberikan 
kepuasan kepada nasabah Simpedes yang datang langsung di PT. Bank Rakyat Indonesia (Persero),Tbk. Kantor Cabang Makassar Tamalanrea. Peningkatan tingkat kualitas layanan ini penting dilakukan oleh PT. Bank Rakyat Indonesia (Persero), Tbk. Kantor Cabang Makassar Tamalanrea guna untuk mengetahui karena kekhawatiran sebagian orang terhadap kualitas layanan Teller yang relatif rendah.

Dari uraian permasalahan diatas, maka penulis tertarik untuk melakukan penelitian dengan judul "Pengaruh Kualitas Layanan Teller Bank Terhadap Kepuasan Nasabah Simpedes Pada PT. Bank Rakyat Indonesia (Persero), Tbk. Kantor Cabang Makassar Tamalanrea".

\section{RUMUSAN MASALAH}

Adapun rumusan masalah dalam penelitian ini yaitu, apakah kualitas pelayanan teller berpengaruh terhadap kepuasan nasabah simpedes pada PT. Bank Rakyat Indonesia (Persero), Tbk. Kantor Cabang Makassar Tamalanrea.

\section{TINJAUAN PUSTAKA}

\section{Kualitas Layanan Teller}

\section{a. Pengertian kualitas layanan}

Untuk menentukan tingkat keberhasilan dan kualitas suatu bank adalah kemampuan bank dalam memberikan layanan kepada nasabah. hasibuan mendefinisikan bahwa layanan adalah kegiatan pemberi jasa dari suatu pihak kepada pihak lain.

Menurut Lupiyoadi (2009: 54) layanan adalah setiap tindakan atau kegiatan yang dapat ditawarkan oleh suatu pihak kepada pihak lain, yang pada dasarnya tidak berwujud dan tidak mengakibatkan kepemilikan apapun, dan layanan merupukan perilaku produsen dalam rangka memenuhi kebutuhan dan keinginan konsumen itu sendiri. Atau dengan kata lain bahwa perilaku tersebut dapat terjadi pada saat, sebelum dan sesudah terjadinya transaksi. Pada 
umumnya yang bertaraf tinggi akan menghasilkan kepuasan yang tinggi serta pembelian ulang yang lebih sering.

\section{b. Pengertian teller}

Teller adalah petugas bank yang bertanggung jawab untuk menerima simpanan, mencairkan cek, dan memberikan jasa pelayanan perbankan lain kepada masyarakat, tanda tangan kasir diperlukan sebagai tanda sah suatu dokumen transaksi, pada lembaga perbankan, Teller bekerja di belakang geral/counter (Dokumen BRI, 2012:1).

Teller merupakan petugas Bank yang pekerjaan sehari-harinya yang berhubungan langsung dengan nasabah dan masyarakat umum. Bank harus menyeleksi petugas yang akan ditunjuk sebagai Teller karena cara kerja, sikap dan sifat serta cara pelayanannya kepada nasabah dan masyarakat umum, secara tidak langsung akan mencerminkan keadaan dan reputasi Bank. Sikap dan sifat serta pelayanan Teller dimaksud, harus diawasi secara rutin oleh manajemen terutama Head Teller dan/atau Cash Officer.

\section{c. Pengukuran kepuasan nasabah}

Menurut Kotler dalam Tipjono (2014: 369) terdapat lima indikator dalam mengukur kepuasan nasabah, seperti:

1) Kepuasan pelanggan keseluruhan

Kepuasan nasabah keseluruhan dapat diukur dengan cara mudah yaitu menanyakan langsung kepada nasabah seberapa puas terhadap produk dan atau jasa perusahaan bersangkutan

2) Dimensi Kepuasan Pelanggan/Nasaba

Dimensi kepuasan dapat dilakukan dengan memilah-milah kepuasan nasabah kedalam beberapa komponen. Seperti melakukan identifikasi terhadap dimensi apa saja yang menjadi kepuasan nasabah, meminta ketersediaan nasabah untuk menilai jasa bank berdasarkan item-item spesifik yang disediakan, seperti kecepatan pelayanan atau keramahan staf layanan pelanggan. 
3) Kesesuaian Harapan

Kesesuaian harapan yang dimaksud untuk mengevaluasi apakah pelayanan yang diberikan oleh bank sudah sesuai dengan harapan sebelum nasabah melakukan transaksi di bank.

4) Niat Pembelian Ulang

Yaitu kepuasan pelanggan diukur secara behavioral dengan jalan menyakan apakah pelanggan akan berbelanja atau menggunakan jasa perusahaan lagi. Pelayanan yang berkualitas dapat menciptakan kepuasan konsumen dimana mutu pelayanan tersebut akan masuk kebenak konsumen sehingga dipersepsikan baik.

5) Kesediaan Untuk Merekomendasi

Yaitu kesediaan untuk merekomendasi produk kepada keluarga atau temanya menjadi ukuran pentingn untuk dianalisis dan ditindaklanjuti. Apabila pelayanan yang diterima atau dirasakan sesuai dengan apa yang diharapkan, maka kualitas pelayanan dipersepsikan baik dan memuaskan, sehingga melalui kepuasan itu konsumen akan melakukan pembelian jasa atau memutuskan untuk menggunakan jasa dan pada akhirnya merekomendasikan hal itu kepada orang lain.

\section{d. Simpedes}

Simpedes adalah simpanan masyarakat dalam bentuk tabungan dengan mata uang rupiah yang dapat dilayani di Kantor Cabang Khusus / Kanca / KCP / BRI Unit, yang penyetoran dan pengambilannya tidak dibatasi baik frekuensi maupun jumlahnya sepanjang memenuhi ketentuan yang berlaku (Dokumen BRI,2012:2).

Pada PT. Bank Rakyat Indonesia (Persero),Tbk. Cabang Makassar Tamalanrea dalam menjalankan Peranannya sebagai tempat penitipan dan penyimpanan uang, mengeluarkan sebuah produk tabungan yaitu Tabungan Simpedes BRI (Simpanan 
Tabungan Pedesaan) yang diperuntukan untuk masyarakat luas khususnya didaerah pedesaan. Sebuah produk yang dipasarkan tentunya mempunyai keungulan-keungulan tertentu untuk menarik calon nasabah atau nasabah yang telah mengunakan produk tersebut.

\section{METODE PENELITIAN}

\section{A. LOKASI DAN WAKTU PENELITIAN}

Pelaksanaan penelitian dilakukan pada PT. Bank Rakyat Indonesia (Persero), Tbk. Kantor Cabang Makassar Tamalanrea yang berlokasi di Jalan Perintis Kemerdekaan Km 12 No.01 Kelurahan Kapasa Makassar, Sulawesi Selatan. Waktu penelitian yang dibutuhkan penulis kurang lebih 1 bulan.

\section{B. JENIS DAN SUMBER DATA}

\section{Jenis Data}

Jenis data yang digunakan dalam penelitian ini adalah sebagai berikut :

a. Data kualitatif yaitu data yang diperoleh dari berbagai sumber dalam bentuk catatan berupa study pustaka, literature, serta jurnal-jurnal yang berkaitan dengan penelitian ini.

b. Data kuantitatif yaitu data yang diperoleh dari jumlah nasabah PT. Bank Rakyat Indonesia (Persero) Tbk. Kantor Cabang Makassar Tamalanrea.

\section{Sumber Data}

Sumber data yang dugunakan dalam penelitian ini adalah primer yaitu data yang diperoleh melalui pengamatan langsung dengan cara menyebarkan kuesioner pada nasabah PT. Bank Rakyat Indonesia (Persero) Tbk. Kantor Cabang Makassar Tamalanrea melalui jawaban responden yang diperoleh dari pengisian kuesioner yang disediakan. 


\section{TEKNIK PENGUMPULAN DATA}

Untuk mendapatkan data yang diperlukan dalam penulisan ini maka penulis menggunakan teknik pengumpulan data adalah sebagai berikut:

\section{Kepustakaan}

Teknik pengumpulan data dengan cara mempelajari metode dari literature, buku, internet dan jurnal yang berkaitan dengan penelitian ini.

\section{Kuesioner}

Teknik pengumpulan data yang dilakukan dengan cara memberi seperangkat pertanyaan atau pernyataan tertulis kepada responden untuk dijawab. Responden yang dimaksud dalam penelitian ini adalah nasabah PT. Bank Rakyat Indonesia (Persero), Tbk. Kantor Cabang Makassar Tamalanrea. Biasanya dalam kuesioner disediakan lima pilihan dengan skala format pembobotan data kuesioner sebagai berikut:

$\begin{array}{lll}\text { Sangat Setuju } & \text { (SS) } & \text { diberi skor 5 } \\ \text { Setuju } & \text { (S) } & \text { diberi skor 4 } \\ \text { Cukup Setuju } & \text { (CK) } & \text { diberi skor 3 } \\ \text { Tidak Setuju } & \text { (TS) } & \text { diberi skor 2 } \\ \text { Sangat Tidak Setuju } & \text { (STS) } & \text { diberi skor 1 }\end{array}$

\section{POPULASI DAN SAMPEL}

\section{Populasi}

Popolasi adalah jumlah keseluruhan dari obyek atau unit analisa yang karakteristiknya akan ditetapkan oleh peneliti untuk ditarik kesimpulannya. Target populasi dalam penelitian adalah seluruh nasabah simpedes pada PT. Bank Rakyat Indonesia (Persero),Tbk. Kantor Cabang Makassar Tamalanrea, yang berjumlah 4.516 orang. 


\section{Sampel}

Sampel adalah bagian dari jumlah dan karasteristik yang dimiliki oleh populasi tersebut. Pengambilan sampel dengan menggunakan teknik Accidental sampling (pengambilan sampel secara kebetulan), orang yang diambil sebagai anggota sampel adalah nasabah yang kebetulan ditemukan atau mereka yang mudah ditemui atau dijangkau. Dengan kriteria sampel yaitu nasabah yang pernah melakukan transaksi melalui teller dan sudah tiga tahun menjadi nasabah aktif.

\section{E. DEFINISI OPERASIONAL VARIABEL}

\section{Kualitas Layanan}

Kualitas layanan adalah ukuran sebarapa bagus tingkat layanan mampu dan sesuai dengan ekspektasi pelanggan". Kualitas layanan ditentukan oleh kemampuan perusahaan untuk memenuhi kebutuhan dan keinginan konsumen yang sesuai dengan harapan konsumen. indikator untuk mengukur kualitas layanan adalah sebagai berikut:

a. Tangible (Bukti fisik), kemampuan suatu perusahaan dalam menunjukkan eksistensinya kepada pihak eksternal. Yaitu bukti fisik teller yang dapat dilihat secara langsung oleh nasabah dengan penampilan diri, persiapan, peralatan dan kerapian tempat kerja merupakan bukti nyata dari pelayanan.

b. Reliability (Kehandalan), kemampuan teller yang dapat diandalkan untuk memberikan pelayanan sesuai dengan yang dijanjikan secara akurat dan terpercaya.

c. Responsiveness (ketanggapan), yaitu suatu kebijakan untuk membantu dan memberikan pelayanan yang cepat dan tepat kepada pelanggan, dengan penyampain informasi yang jelas.

d. Ansurance (jaminan dan kepastian), yaitu konsumen akan dilayani dengan baik oleh karyawan yang memiliki tingkat 
kompetensi yang memadai dan mampu memberi rasa aman dan nyaman.

e. Empathy (perhatian), yaitu memberikan kepedulian dan perhatian individu atau pribadi yang diberikan perusahaan kepada konsumennya dengan berupayan memahami keinginan pelanggan.

\section{Kepuasan Nasabah}

Kepuasan nasabah adalah keadaan yang dicapai bila produk sesuai dengan kebutuhan atau harapan konsumen dan bebas dari kekurangan.

a. Kepuasan pelanggan keseluruhan

Kepuasan nasabah keseluruhan dapat diukur dengan cara mudah yaitu menanyakan langsung kepada nasabah seberapa puas terhadap produk dan atau jasa perusahaan bersangkutan

b. Dimensi Kepuasan Pelanggan/Nasabah

Dilakukan dengan memilah-milah kepuasan nasabah kedalam beberapa komponen. Seperti melakukan identifikasi terhadap dimensi apa saja yang menjadi kepuasan nasabah, meminta ketersediaan nasabah untuk menilai jasa bank berdasarkan item-item spesifik yang disediakan, seperti kecepatan pelayanan atau keramahan staf layanan pelanggan.

c. Kesesuaian Harapan

Kesesuaian harapan yang dimaksud untuk mengevaluasi apakah pelayanan yang diberikan oleh bank sudah sesuai dengan harapan sebelum nasabah melakukan transaksi di bank.

d. Niat Pembelian Ulang

Yaitu kepuasan pelanggan diukur secara behavioral dengan jalan menyakan apakah pelanggan akan berbelanja atau menggunakan jasa perusahaan lagi. Pelayanan yang berkualitas dapat menciptakan kepuasan konsumen dimana mutu pelayanan 
tersebut akan masuk kebenak konsumen sehingga dipersepsikan baik.

e. Kesediaan Untuk Merekomendasi

Yaitu kesediaan untuk merekomendasi produk kepada keluarga atau temanya menjadi ukuran pentingn untuk dianalisis dan ditindak lanjuti.

\section{F. ANALISIS DATA}

Untuk menguji hipotesis yang telah dikemukakan, maka penulis menggunakan beberapa metode analisis sebagai berikut :

\section{Uji Instrument}

a. Uji Validitas

Sugiyono (2014:35) pengujian ini dilihat dari valid atau tidaknya data yang diolah, instrument yang valid berarti alat ukur yang digunakan untuk mendapatkan data tersebut valid. Validitas dilakukan dengan menggunakan program spss, dengan kriteria sebagai berikut:

1) Jika $r$ Hitung < r Tabel, maka pernyataannya dinyatakan valid

2) Jika $r$ Hitung > r Tabel maka pernyataannya dinyatakan tidak valid.

b. Uji reliabilitas

Uji reliabilitas digunakan untuk mengetahui keandalan instrument kuesioner yang digunakan dalam penelitian (Sugiyono 2014: 119). Pada analisis ini digunakan Cronbach Alpha dengan ketentuan :

1) Apabila nilai yang ditunjukkan dalam Cronbach Alpha $\geq 0.6$ maka kuesioner dinyatakan reliable.

2) Apabila nilai yang ditunjukkan dalam Cronbach Alpha < 0.6 maka kuesioner dinyatakan tidak reliable.

\section{Uji Normalitas}

Digunakan untuk mengetahui apakah regresi telah memenuhi asumsi normal atau tidak. Cara untuk mengetahui 
regresi normal atau tidak dengan melihat titik-titik pada output SPSS mengikuti garis diagonal atau tidak. Apabila titk-titik mengikuti garis diagonal maka regresi dinyatakan telah memenuhi asumsi normalitas.

\section{Analisis Regresi Linear Sederhana}

Teknik regresi sederhana digunakan untuk mengetahui arah hubungan antara variabel independen dengan variabel devenden apakah positif atau negative dan untuk memprediksi nilai variabel indenpenden mengalami kenaikan dan penurunan

\section{Pengujian Hipotesis (Uji t parsial)}

Uji t dimaksudkan untuk mengetahui apakah secara parsial variabel indevenden (bebas) berpengaruh secara signifikan atau tidak terhadap variabel devenden (terikat). Hasil uji t dapat dilihat pada output SPSS tabel Coefficients.

\section{Koefisien Determinasi $\left(\mathbf{R}^{2}\right)$}

Menurut Basuki dan Prawoto (2016:17) bahwa koefisien determinasi $\left(R^{2}\right)$ adalah koefisien yang menjelaskan hubungan antara variabel independen dan variabel dependen. Melalui nilai koefisien determinasi yang ditunjukkan oleh $R$ square $\left(R^{2}\right)$ mendekati angka 1, maka dikatakan semakin kuat kemampuan variabel bebas model regresi tersebut dalam menerangkan variasi variabel terikatnya. Sebaliknya jika $\left(R^{2}\right)$ mendekati angka 0 (nol) maka semakin lemah variabel bebas menerangkan variabel terikat

\section{KESIMPULAN}

Penelitian ini mengenai pengaruh kualitas layanan teller bank terhadap kepuasan nasabah simpedes pada PT. Bank Rakyat Indonesia (Persero), Tbk. Kantor Cabang Makassar Tamalanrea yang mengambil data tahun 2017-2019.

Hasil penelitian dapat ditarik kesimpulan bahwa: Kualitas layanan teller bank berpengaruh positif dan signifikan terhadap 
kepuasan nasabah simpedes pada PT. Bank Rakyat Indonesi:

(Persero), Tbk. Kantor Cabang Makassar Tamalanrea

\section{DAFTAR PUSTAKA}

Bank Indonesia, 1998. UU No. 10 tahun 1998, tentang Perbankan, Jakarta

Daryanto, Ismanto Setyobudi, 2012, Konsumen dan Pelayanan Prima. Yogyakarta : Gava Media.

Fandy, Tjiptono, 2011, Service Management Mewujudkan Layanan Prima. Edisi 2. Yogyakarta : Andi

Klavei Priska Lorry, 2015, Pengaruh Kualitas Pelayanan Terhadap Kepuasan Nasabah Pada PT. Bank Rakyat Indonesia (Persero) Tbk. Skiripsi. Manado : Politeknik Negeri Manado.

Kartika, 2017, Analisis Kualitas Pelayanan Teller Terhadap Kepuasan Nasabah Bank Rakyat Indonesia KCP Sultan Alauddin, Makassar : Fakultas Ekonomi dan Bisnis Universitas Muhammadyah Makassar.

Kotler, P. dan Keller, K, L. 2012. Manajemen Pemasaran, edisi 13 Jilid 1 dan 2, Alih Bahasa : Bob Sabran, Erlangga, Jakarta.

Kotler, P. dan Keller, K, L. 2012. Manajemen Pemasaran, edisi 13 Jilid 1 dan 2, Alih Bahasa : Bob Sabran, Erlangga, Jakarta.

Lupiyoadi, R, dan Hamdani, A. 2009. Manajemen Pemasaran Jasa. Jakarta : Salemba Empat

Lupiyoadi, R, dan Hamdani, A. 2006. Manajemen Pemasaran Jasa. Jakarta : Salemba Empat

Tjipjono, Fandi. 2008. Pemasaran Jasa. Malang : Bayumedia

Tjipjono, Fandi. 2008. Pemasaran Jasa. Malang : Bayumedia

Supranto, 2006, Mengukur Tingkat Kepuasan Pelanggan dan Konsumen, Jakarta:Rineka Cipta.

Sugiyno. 2007. Metode Penelitian Pendidikan Pendekatan Kuantitatif, Kualitatif, dan R\&D. Bandung: Alfabeta. 
Sugiyno. 2007. Metode Penelitian Pendidikan Pendekatan Kuantitatif, Kualitatif, dan R\&D. Bandung: Alfabeta. 

